\title{
Palladium-Catalyzed Diamination of Olefins
}

Key words

palladium

olefin diamination

C-H activation

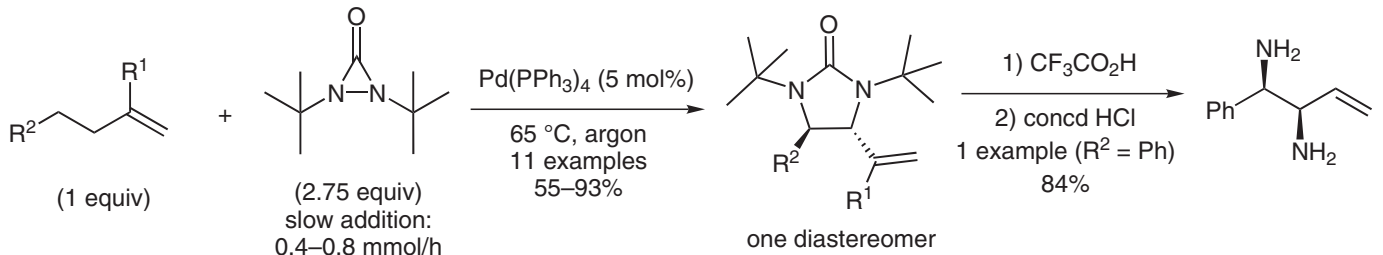

$\mathrm{R}^{1}=\mathrm{H}, n-\mathrm{Bu}, \mathrm{Ph}, \mathrm{OMe}$

$\mathrm{R}^{2}=\mathrm{Ph}, \mathrm{Et}, n$-Hex, $\mathrm{CH}_{2} \mathrm{OBn}, \mathrm{CH}_{2} \mathrm{O} n$-Hex, $\mathrm{CH}_{2} \mathrm{CHCH}_{2}$, Me

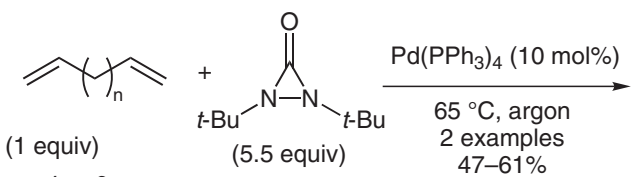<smiles>C=C[C@H]1[C@H]2CC[C@@H]3[C@H]([C@H](CC(C)(C)C)N2C(=O)N1C(C)(C)C)N(C(C)(C)C)C(=O)N3C(C)(C)C</smiles>

if $\mathrm{n}=6:$ meso/dl $=1: 1$<smiles>C=C[C@H]1C(C2C(C(C)(C)C)N(CC(C)(C)C)C(=O)N2C(C)(C)C)N(C(C)(C)C)C(=O)N1C(C)(C)C</smiles>

if $\mathrm{n}=4$ : single diastereomer

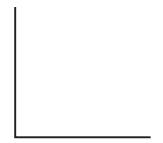<smiles>C=CCCC1[C@H](C=C)N(CC(C)C)C(=O)N1C(C)(C)C</smiles><smiles>C=C/C=C/C1[C@H](C=C)N(C(C)(C)C)C(=O)N1C(C)(C)C</smiles><smiles>C=CC</smiles>

Significance: Complementary to previous approaches to diaminate olefins and as an extension to the group's previous work in the area $(\mathrm{H}$. Du, B. Zhao, Y. Shi J. Am. Chem. Soc. 2007, 129, 762), terminal olefins were diaminated at allylic and homoallylic carbons by a $\mathrm{Pd}$-catalyzed $\mathrm{C}-\mathrm{H}$ insertion under solvent-free conditions. The nitrogen source is di-tert-butyldiaziridinone, which can be synthesized in a few steps. The scope encompasses both monosubstituted and 1,1-disubstituted terminal olefins, and the resulting products can be converted into the free diamine by treatment with TFA and concentrated acid. Diamination is also possible, with 1,9-decadiene producing a 1:1 mixture of diastereomers and with 1,7octadiene producing a single diastereomer.
Comment: Diamination of olefins is a potentially efficient strategy for synthesizing vicinal diamines. The present method needs to be solvent-free and have slow addition of the nitrogen source. The diamination results for 1,9-decadiene versus 1,7-octadiene suggest that the first diamination influences the stereochemical outcome of the second diamination unless the two olefins are too far apart. Although the exact mechanism is unknown, intermediates $\mathbf{A}$ and $\mathbf{B}$ have been isolated and both shown to lead to the product, which suggests that a conjugated diene is formed after the first diamination. The authors also speculate that $\mathrm{Pd}(0)$ inserts into the $\mathrm{N}-\mathrm{N}$ bond of the diaziridinone, followed by coordination with the olefin, $\pi$-allyl formation, and nucleophilic attack of the amine moieties onto the olefin to furnish the product. A means of producing differentially protected diamines would be very attractive. 